\title{
Multi-objective optimal placement of distributed generations for dynamic loads
}

\author{
Shah Mohazzem Hossain ${ }^{1}$, Abdul Hasib Chowdhury ${ }^{2}$ \\ ${ }^{1}$ Department of EECE, Military Institute of Science and Technology (MIST), Bangladesh \\ ${ }^{2}$ Department of EEE, Bangladesh University of Engineering and Technology (BUET), Bangladesh
}

\begin{tabular}{l}
\hline Article Info \\
\hline Article history: \\
Received Nov 25, 2018 \\
Revised Dec 20, 2018 \\
Accepted Mar 10, 2019 \\
\hline
\end{tabular}

\section{Keywords:}

Distributed generation

Dynamic loads

Optimal placement

\begin{abstract}
Large amount of active power losses and low voltage profile are the two major issues concerning the integration of distributed generations with existing power system networks. High $R / X$ ratio and long distance of radial network further aggravates the issues. Optimal placement of distributed generators can address these issues significantly by alleviating active power losses and ameliorating voltage profile in a cost effective manner. In this research, multiobjective optimal placement problem is decomposed into minimization of total active power losses, maximization of bus voltage profile enhancement and minimization of total generation cost of a power system network for static and dynamic load characteristics. Optimum utilization factor for installed generators and available loads is scaled by the analysis of yearly load-demand curve of a network. The developed algorithm of $\mathrm{N}$-bus system is implemented in IEEE-14 bus standard test system to demonstrate the efficacy of the proposed method in different loading conditions.
\end{abstract}

Copyright (c) 2019 Institute of Advanced Engineering and Science. All rights reserved.

\section{Corresponding Author:}

Shah Mohazzem Hossain

Departement of Electrical, Electronic and Communication Engineering (EECE)

Military Institute of Science and Technology (MIST)

Dhaka-1216, Bangladesh.

Email: soneteee@gmail.com; mohazzem_hossain@eece.mist.ac.bd

\section{INTRODUCTION}

Neoteric power system network is incessantly being faced with an ever thriving load demand with accretive load results aggravated burden and palliation of system voltage magnitude. A real power network has emblematic behaviour that node voltages are waned at long distance bus location from substation buses. Inappropriate placement of new distributed generations (DG) is the main cause of voltage droop. Even a certain industrial area with critical loading, it may lead to voltage collapse of the whole network. Thus, optimal placement of DG is an exigent issue to ameliorate the voltage magnitude for avoiding a sudden voltage collapse. A distribution network causes a significant amount of power losses and a drop in voltage magnitude along the radial lines due to its high $R / X$ ratio than transmission networks [1]. However, financial issues as well as overall efficiency of the distribution utilities is being influenced by these non-negligible losses. Overall efficiency of power delivery towards consumers is being boosted by forcing the electrical utilities to abate the system losses at distribution ends. A good number of arrangements has already been worked out to curtail these losses like optimal distributed generator placement, network reconfiguration, shunt capacitor placement for reactive power compensation etc. [2].

Integration of DG at optimal location can indulgence in reducing energy losses, peak demand losses and enhancement of voltage profile, network stability and power factor of the whole network [3]. Thus, new DGs are needed to be connected in such a manner that it abstains degradation of power quality and reliability. Infelicitous allocation of DG in terms of its bus location may lead to rise in fault currents, causes voltage variations, intervene in voltage-control processes, increase losses, system capital and operating costs etc. 
Evaluation of the technical impacts of DG is very tenacious and arduous work. Moreover, installation and placement of DG units is not straight-forward and need to be precisely alluded especially for load varying conditions with different variables like power loss, voltage profile, generation cost, load factor and reliability [4].

A lot of complexity arises during optimization of these non-commensurable variables with different types of equality and inequality constraints. A good number of optimization techniques and algorithm have already proposed including analytical approach, computational approach and different types of artificial intelligence approach to solve these tenacious optimization problem. A simple analytical method is applied for real power loss abatement and voltage profile enhancement based on voltage sensitivity index and power flow analysis by using forward-backward sweep method [5]. In mathematical approach based on power loss index and load flow analysis, total active power loss of distribution lines with DG is enumerated in newton-raphson extended method [6]. An alternate solution is vindicated to assuage the impact of DG reactive power demand in transmission voltages and go beyond the distribution voltage rise barrier such that more DG is connected. The fixed power factors of the installed generators and tap setting transformer is evaluated by linear programming formulation technique [7].

In this modern era, analytical and computational optimization techniques are being phased out by the most promising artificial intelligence techniques including especially genetic algorithm [8], particle swarm optimization [9-11], artificial neural network [12-13], harmony search differential operator [14], immune algorithm [15] and clonal selection etc. [16]. Genetic algorithm (GA) with real codes and backward forward power flow method based on 20 bus distribution network is used to optimally locate DG for minimum system losses and maximum voltage in radial distribution networks. The optimization problem with minimization of real power loss subjected to different constraints is solved on the basis of active power loss sensitivity of real power injection through DG [17].

Particle swarm optimization (PSO) based hybrid objective approach for optimal placement of DG is used with power loss reduction and reliability improvement index for only active power losses [18]. Evolutionary PSO has provided superior results with less number of iteration, computation time and also avoid the problem of being trapped in a local minimum by selecting the survival particles to remain in the next iteration [19].

Advanced pareto-front non-dominated sorting with fuzzy decision technique has recently applied to essence the trade-off solution set from different objective functions like power loss, voltage stability and deviation optimization in IEEE-33 bus test system [10]. A smart grid system with DG is developed in immune algorithm based on the cost of different sections i.e. environmental compensation, traditional DG capacity, DG operation and maintenance, purchased power and network loss for IEEE-30 bus test system. The optimal solution in dynamic programming method is effectively resolved the DG planning problem of smart grid system. In a hybrid technique consisting GA and artificial neural network is applied for placing DGs at worthy locations and evaluating generated power based on load variations to ensure optimal power quality and reliability [20].

Optimal location is determined considering the power losses at each DG connected bus by using the newton-raphson extended method in neplan simulation technique [8]. In combination of GA and PSO is implemented to minimize real power losses and increase voltage stability of a 52 bus system with load uncertainty during optimal placement [21].

A new methodology using simple data from distribution network operators control center of the region connecting feeders is also used to determine the optimal location of medium size DGs with uncertain topologies in Monte Carlo simulation analysis [22]. Algorithm has also been developed to optimize both power losses and voltage profile by bus injection to branch current and branch-current to bus voltage matrices. In most of the proposed techniques, generation cost is ignored and only static loads are considered during optimal placement of distributed generators.

\section{PROBLEM STATEMENT FORMULATION}

Multi-objective non-commensurable functions with a number of equality and inequality constraints are being optimized for the DG placement in the power system network.

$$
\text { Optimize } F(x)=\left[\min F_{\text {Loss }}(x) \times \max V_{\text {bus }}(x)\right] \times \min F_{\text {cost }}(x)
$$

Where, $F_{\text {Loss }}(x)=$ System active power loss

$V_{\text {bus }}(x)=$ Improved bus voltage profile $\&$

$F_{\text {cost }}(x)=$ Total generation cost of the network 


\subsection{Minimization of system power loss}

As the current entering a bus is considered positive and leaving the bus is negative that causes correspondingly the real power and reactive power entering that bus is positive and negative. The complex power at bus-i of Figure 1 is then given by,

$$
P_{i}-j Q_{i}=V_{i}^{*} I_{i}=V_{i}^{*} \sum_{k=1}^{n} Y_{i k} V_{k}
$$

From per-unit system, $S_{i k}=P_{i k}+j Q_{i k}=V_{i} I_{i k}{ }^{*}$

$$
\text { Where, } I_{i k}=\left[\frac{P_{i k}+j Q_{i k}}{V_{i}}\right]^{*}
$$

Taking only the magnitude, $\left|I_{i k}\right|=\frac{\sqrt{P_{i k}{ }^{2}+Q_{i k}{ }^{2}}}{\left|V_{i}\right|}$

$$
\begin{aligned}
& \left|I_{i k}\right|^{2}=\frac{P_{i k}{ }^{2}+Q_{i k}{ }^{2}}{\left|V_{i}\right|^{2}} \\
& \left|I_{i k}\right|^{2} \times R_{i k}=\frac{{P_{i k}}^{2}+Q_{i k}{ }^{2}}{\left|V_{i}\right|^{2}} \times R_{i k} \\
& P_{i k_{\text {Loss }}}=\frac{P_{i k}{ }^{2}+Q_{i k}{ }^{2}}{\left|V_{i}\right|^{2}} \times R_{i k}
\end{aligned}
$$

The total active power loss for $\mathrm{N}$ number of bus sections is expressed as

$$
\min F_{\text {Loss }}=P_{T_{\text {Loss }}}=\sum_{i, k ; i \neq k} P_{i k_{\text {Loss }}}
$$

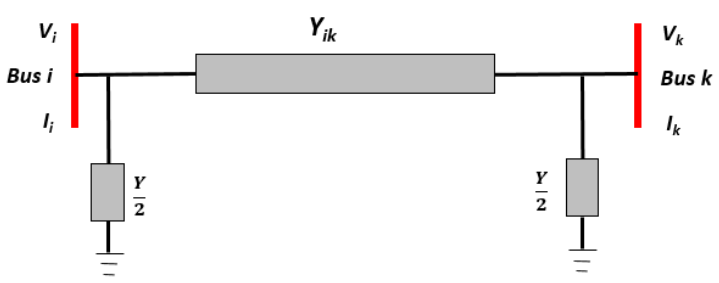

Figure 1. Single bus system network

\subsection{Voltage profile maximization}

Bus voltage profile is analysed by gauss-seidal load flow study where, updated bus voltage profile value is determined in following way from the complex power equation.

$$
V_{i}=\frac{1}{Y_{i i}}\left[\frac{P_{i}-j Q_{i}}{V_{i}{ }^{*}}-Y_{i 1} V_{l}-Y_{i 2} V_{2}-Y_{i 3} V_{3}-\cdots \cdots \cdots-Y_{i n} V_{n}\right]
$$

Updated final total bus voltage of all buses is represented by

$$
\max V_{B u s}=\sum_{i=1}^{N_{\text {bus }}} V_{i}
$$

\subsection{Generation cost optimization}

The total costs include the fixed costs during initial investment and variable costs including the maintenance cost and utilization factor of DG units which is expressed through following equation.

$$
\min F_{\text {cost }}=a+b P+c P^{2}+d P^{3}
$$

Where $\mathrm{a}, \mathrm{b}, \mathrm{c}, \mathrm{d}$ is the corresponding coefficient value for fixed and variable cost of the network.

\section{SYSTEM CONSTRAINTS}

The objective functions for the DG placement problem is needed to meet certain security constraints and network constraints. $P_{s y s}$ and $Q_{s y s}$ are injected active and reactive powers to the distribution network 
by sub-transmission network. $P_{D G}$ and $Q_{D G}$ are associated active and reactive powers of DGs. $P_{d}$ and $Q_{d}$ are total power demand of network loads. $P_{\text {Loss }}$ and $Q_{\text {Loss }}$ are both active and reactive power losses of the network. Network power balance equation for the network is expressed as

$$
\begin{aligned}
& P_{\text {sys }}+P_{D G}=P_{d}+P_{\text {Loss }} \\
& Q_{s y s}+Q_{D G}=Q_{d}+Q_{\text {Loss }}
\end{aligned}
$$

Electrical network contains some imperative constraints like bus voltage $\left(V_{i}\right)$, thermal current $\left(I_{i j}\right)$ limits of each line and power limits of connected DG.

$$
\begin{aligned}
& V_{i}^{\text {min }} \leq V_{i} \leq V_{i}^{\text {max }} \\
& I_{i j} \leq I_{i j}^{\text {max }} \\
& P_{D G^{\text {min }}} \leq P_{D G} \leq P_{D G^{\text {max }}} \\
& Q_{D G}^{\text {min }} \leq Q_{D G} \leq Q_{D G^{\text {max }}}
\end{aligned}
$$

\section{MODEL SYSTEM OPTIMIZATION}

In this work, multi-objective optimal placement problem is decomposed into different types of real time variable functions. An algorithm is developed in MATLAB to optimize these variables in N-bus system network. The developed technique is applied in IEEE-14 bus test systems of Figure 2 where, bus- 1 is selected as slack bus of the network. Bus-13 and bus-14 are generator $(P V)$ bus, except all rest are load $(P Q)$ buses. The line impedances with the line charging admittances, bus voltage magnitudes, installed generator rating, operating cycle, cost coefficient of the network is shown in Table 1 to Table 4 . The operation of power systems has been complicated by the rapid diversification of loads in recent days especially in industrialize areas. Load characteristics analysis has become one of the most significant part in modern energy management system to find the optimal bus location of DG and network reliability. Unstable loading conditions causes difficulties

\begin{tabular}{|c|c|c|c|c|}
\hline \multirow{2}{*}{\multicolumn{2}{|c|}{$\begin{array}{c}\text { Line } \\
\text { (Bus to Bus) }\end{array}$}} & \multicolumn{2}{|c|}{ Impedance $(\mathrm{pu})$} & \multirow{2}{*}{$\begin{array}{c}\text { Line Charging } \\
(Y / 2)\end{array}$} \\
\hline & & $R$ ohm & $X$ ohm & \\
\hline 1 & 2 & 0.01938 & 0.05917 & 0.0264 \\
\hline 1 & 5 & 0.05403 & 0.22304 & 0.0219 \\
\hline 2 & 14 & 0.04699 & 0.19797 & 0.0187 \\
\hline 2 & 4 & 0.05811 & 0.17632 & 0.0246 \\
\hline 2 & 5 & 0.05695 & 0.17388 & 0.017 \\
\hline 14 & 4 & 0.06701 & 0.17103 & 0.0173 \\
\hline 4 & 5 & 0.01335 & 0.04211 & 0.0064 \\
\hline 4 & 7 & 0.0121 & 0.20912 & 0.0014 \\
\hline 4 & 13 & 0.0211 & 0.55618 & 0.00241 \\
\hline 5 & 6 & 0.03217 & 0.25202 & 0.0014 \\
\hline
\end{tabular}
in determining the available load in a certain time period. Mostly, load values are forecasted from the available load curves of the particular section of a network.

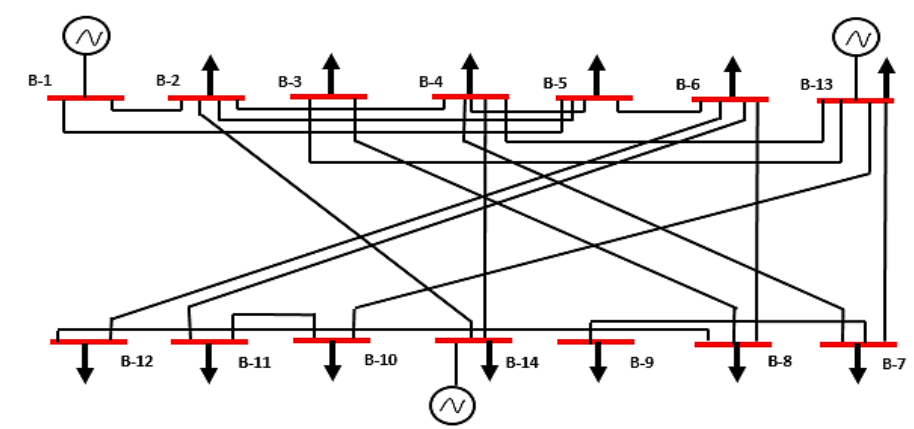

Figure 2. IEEE-14 bus system network

Table 1. Line impedances and line charging admittances

\begin{tabular}{ccccc}
\hline \multicolumn{2}{c}{ Line } & \multicolumn{2}{c}{ Impedance $(\mathrm{pu})$} & $\begin{array}{c}\text { Line Charging } \\
\text { (Bus to Bus) }\end{array}$ \\
\hline 6 & 11 & 0.09498 & 0.1989 & 0.00611 \\
6 & 12 & 0.12291 & 0.25581 & 0.00121 \\
6 & 8 & 0.06615 & 0.13027 & 0.0014 \\
7 & 9 & 0.04131 & 0.17615 & 0.0111 \\
7 & 13 & 0.02133 & 0.11001 & 0.00131 \\
13 & 10 & 0.03181 & 0.0845 & 0.0164 \\
13 & 3 & 0.12711 & 0.27038 & 0.0025 \\
10 & 11 & 0.08205 & 0.19207 & 0.0114 \\
12 & 8 & 0.22092 & 0.19988 & 0.0164 \\
8 & 3 & 0.17093 & 0.34802 & 0.00347 \\
\hline
\end{tabular}


Table 2. Bus voltage magnitudes and generator rating

\begin{tabular}{cccccc}
\hline \multirow{2}{*}{ Bus Type } & \multirow{2}{*}{ Bus No. } & \multicolumn{2}{c}{ Bus Voltage } & \multicolumn{2}{c}{ Power Generated } \\
& & Magnitude $(\mathrm{pu})$ & Angle $(\mathrm{deg})$ & $P(\mathrm{MW})$ & $Q$ (MVAR) \\
\hline Slack & 1 & 1.06 & 0 & 40 & - \\
$P V$ bus & 13 & 1.01 & - & 35 & - \\
DG & 14 & 1.045 & - & 25 & - \\
\hline
\end{tabular}

Table 3. Installed generator operating cycle

\begin{tabular}{cccccc}
\hline Generator & $\begin{array}{c}\text { Max } \\
(\mathrm{MW})\end{array}$ & $\begin{array}{c}\text { Mi } \\
(\mathrm{MW})\end{array}$ & $\begin{array}{c}\text { Up Time } \\
(\mathrm{Hr})\end{array}$ & $\begin{array}{c}\text { Down Time } \\
(\mathrm{Hr})\end{array}$ & $\begin{array}{c}\text { Priority } \\
\text { Order }\end{array}$ \\
\hline Gen-1 & 40 & 20 & 6 & 3 & 1 \\
Gen-2 & 35 & 10 & 5 & 2 & 2 \\
Gen-3 & 25 & 8 & 4 & 2 & 3 \\
DG & 3 & 0.5 & 2 & 1 & 4 \\
\hline
\end{tabular}

Table 4. Installed generator cost coefficient values

\begin{tabular}{ccccc}
\hline Generator & $a$ & $b$ & $c$ & $d$ \\
\hline Gen-1 & 25.5 & 12.3 & 0.2 & 206 \\
Gen-2 & 27.62 & 15.4 & 2.2 & 281 \\
Gen-3 & 20.41 & 11.7 & 1.7 & 250 \\
DG & 22.21 & 18.31 & 15.23 & 505 \\
\hline
\end{tabular}

A load curve reflects the change of electrical power consumption by consumers over a particular time cycle like a day, week, month or year. Cognisant values of consumer's load make the load calculation very much straightforward in any section. Consumers factor and time factor mainly influence the dynamic load modelling and forecasting. The customer factor is related with the total number, type and power consumption rate of the installed electrical appliances in consumer's end. The electrical load usually varies with time depending on human and pecuniary activity. There is more load in the day time and less load at night. Large amount of load variation occurs in week days compared with weekend. This cyclic time dependency forced to peruse the loads in hourly, daily, weekly or yearly basis. Climate change has also an impact on load characteristics especially change of humidity results variation in use of electrical appliances. Real power system network causes a significant voltage drops and higher power loss due to this natural load factors. Interconnection of DG to the grid may have different implications on the distribution network due to the load characteristics. In this work, worst possible load-demand curve of a zone is analysed to ensure optimal placement of DG [23]. Dynamic load connected 13 buses are analysed on basis of their data of respective zone's yearly load-demand curves of the network which are depicted in Figure 3 and Figure 4.

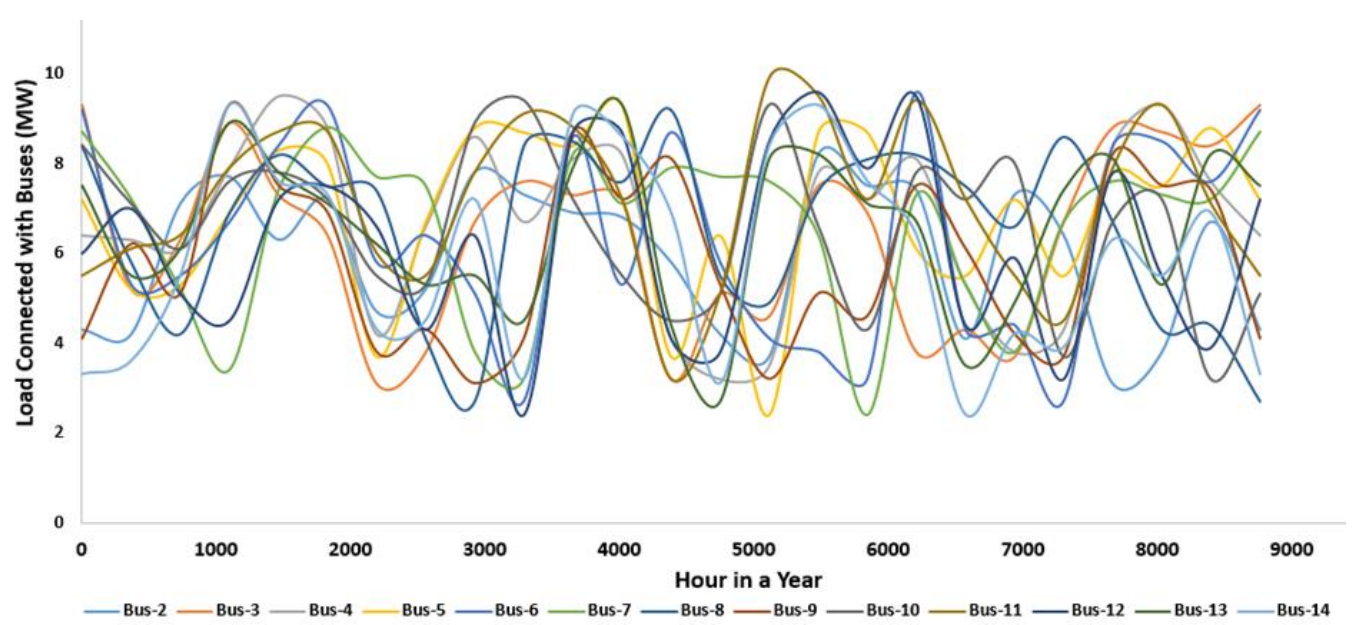

Figure 3. Load connected buses real power variations 


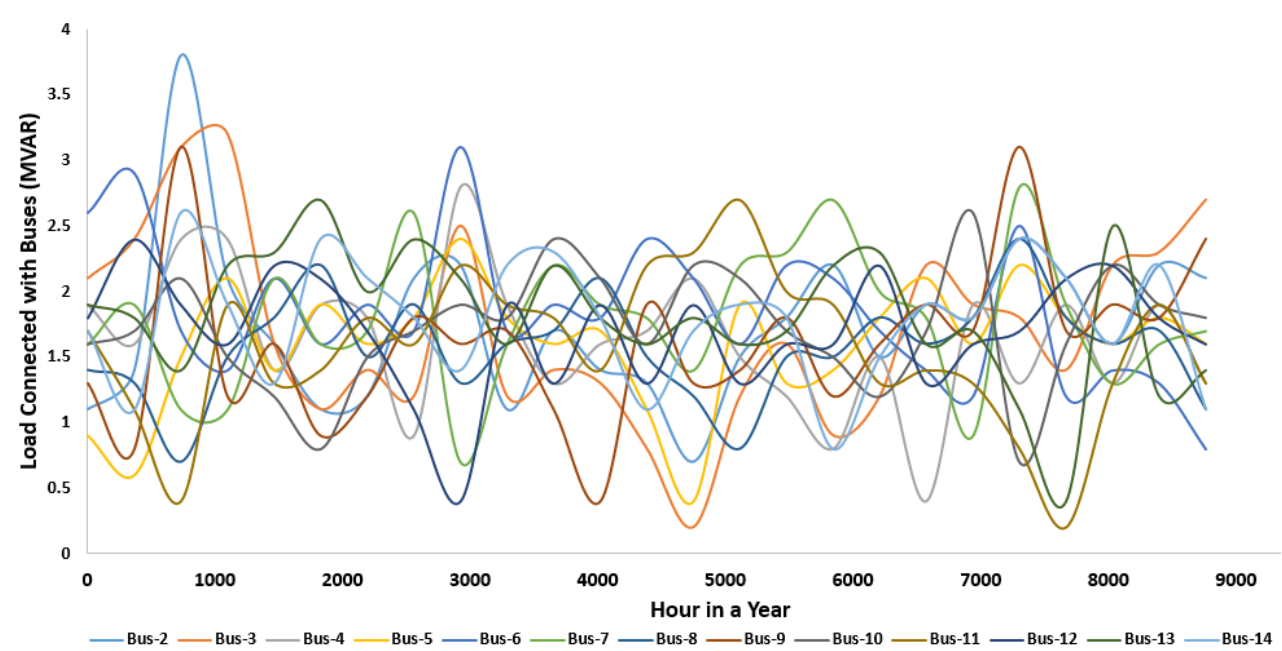

Figure 4. Load connected buses reactive power variations

\section{PROCESS DESCRIPTION}

A load-flow study has done to determine the voltages, currents and real and reactive power flows in a network under a given load conditions for various hypothetical situations. Non-linear basic power flow equations are solved by using gauss-seidal iteration method. Self-admittance of each bus and the mutual admittance between the buses forms admittance matrix using the value of line impedances and line charging admittances of Table $1.1+j 0$ per unit voltage value is initialized for all buses to find-out the unknown bus voltage magnitudes and angles of the $P Q$ buses and angles of the $P V$ buses. After convergence progress of iteration solutions final bus voltage is determined beyond the tolerance level. Voltage difference between two buses causes the current flow to the network. Due to the presence of resistive property a certain amount of power is lost in the network. Large distance of the network line corresponds the large amount of power loss. While total generation cost of the system depends on its capability to meet the maximum demand with minimum power loss in the network. Generator active operating hour is a concerning issue for estimating the overall cost of the system by using the cost-coefficient values of Table 4. Usually DG units are being used to meet up the peak load or certain demand of the load in the network. Calculated active operating hour using respective generator characteristics of Table 3 in different time span of a year for the selective section of the model network in is shown Figure 5. The flow chart to determine the summation of all bus voltage, line to line loss and generation cost is depicted in Figure 6 to Figure 8.

In the first stage of multi-objective optimization process candidate DG is placed in all available buses independently except slack bus to calculate the change of bus voltage profiles using gauss-seidal iteration method. The loss factor is determined to find the amount of power loss in a particular line with respect to the change in bus voltage profiles. Then calculated cost factor is used to estimate the total generation cost with respect to the change in line losses. A heuristics approach is used in the second stage through lagrangian multiplier function to find the optimal bus location for integration of DG units in a power system network. Flow chart for optimization process is depicted in Figure 9.

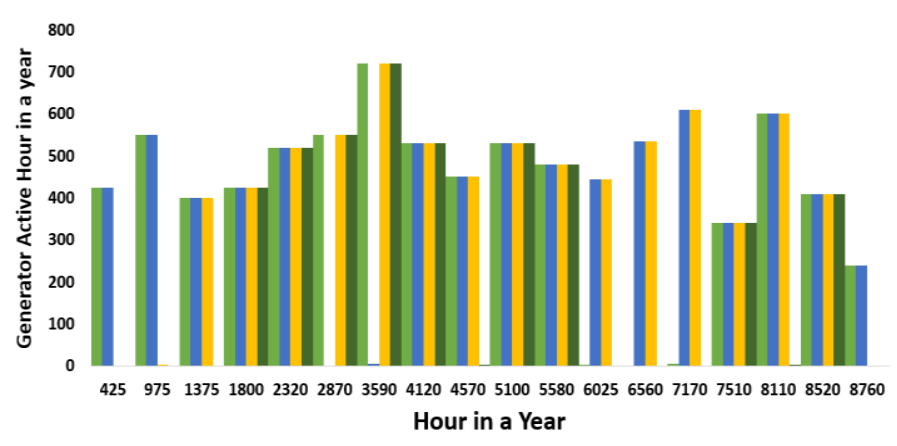

Figure 5. Installed generators active operating hour 


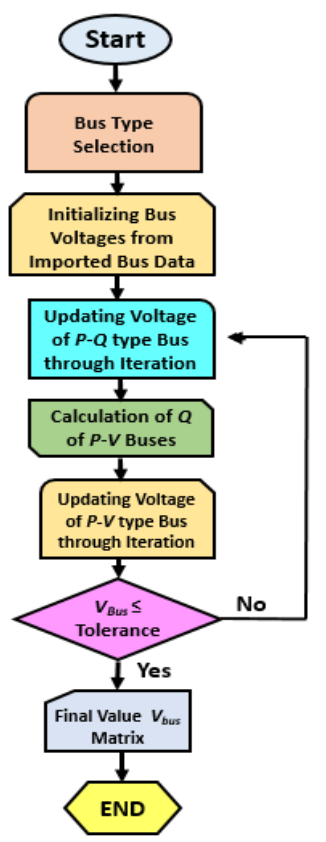

Figure 6. Flow chart for bus voltage calculation

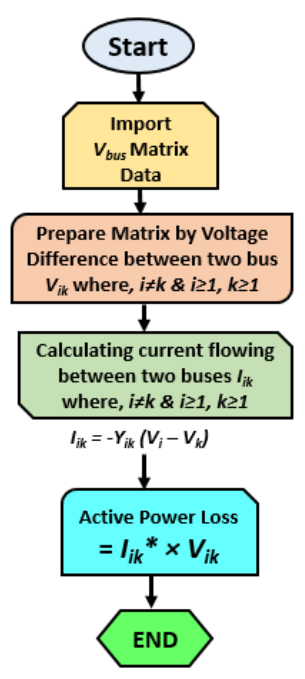

Figure 7. Flow chart for line to line loss calculation

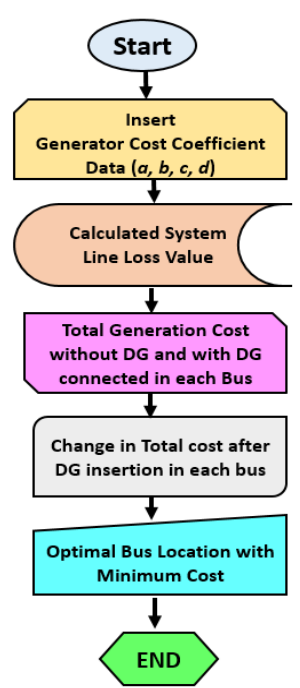

Figure 8. Flow chart for generation cost calculation

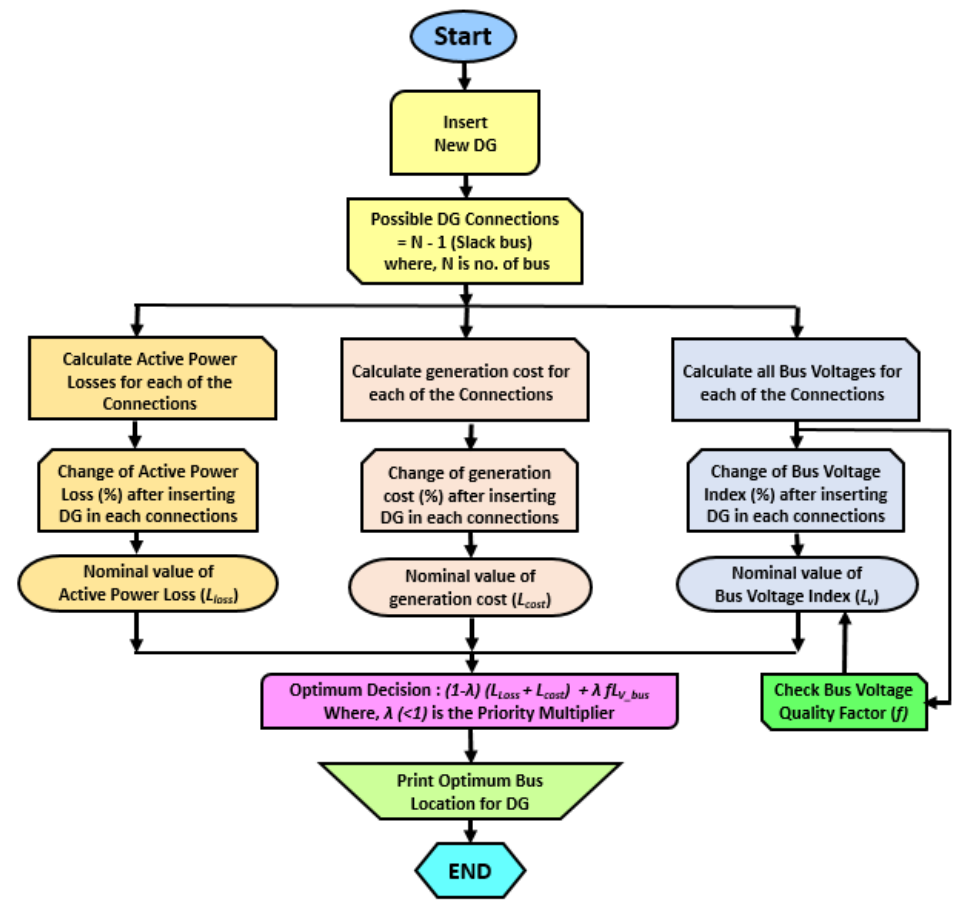

Figure 9. Flow chart for optimization of bus voltage and line to line loss of the network

\section{RESULTS AND DISCUSSIONS}

In the process of optimization selected new DG is connected to all possible bus location to find the change in bus voltage, line loss and generation cost with respected to normalized system values. Change of bus voltage magnitudes after DG insertion in each bus of the network except the swing bus is depicted in Figure 10 to Figure 13. Optimal bus location is selected when maximum voltage profile improvement, minimum power loss and generation cost is ensured in the network. Total change in bus voltage, power loss and generation cost for DG placement in each bus location is depicted in Figure 14 to Figure 16. Optimal bus location for the given network of dynamic loads is selected bus number 12 from the Table 5 . 


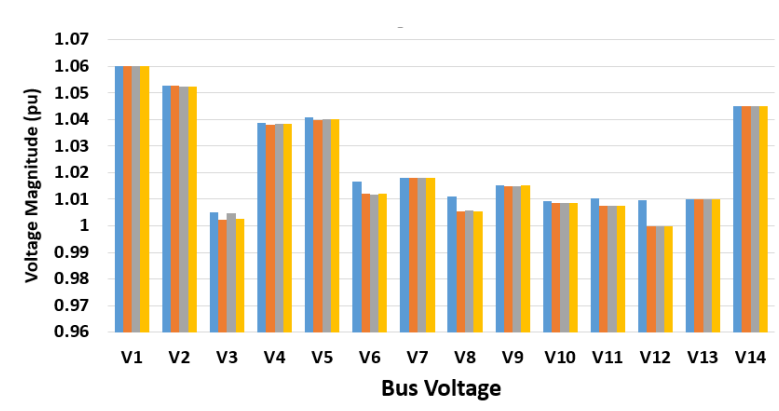

Without DG $\quad$ DG at Bus-2 $\square$ DG at Bus-3 $\square$ DG at Bus-4

Figure 10. Change in each bus voltage magnitudes after DG insertion at Bus-2 to Bus-4

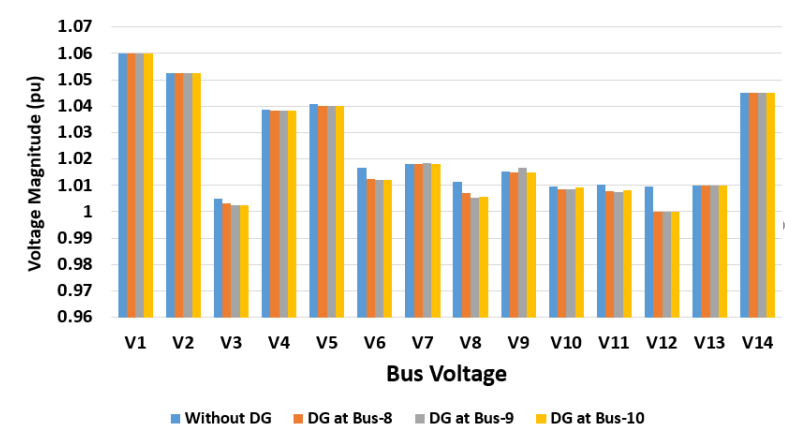

Figure 12. Change in each bus voltage magnitudes after DG insertion at Bus-8 to Bus-10

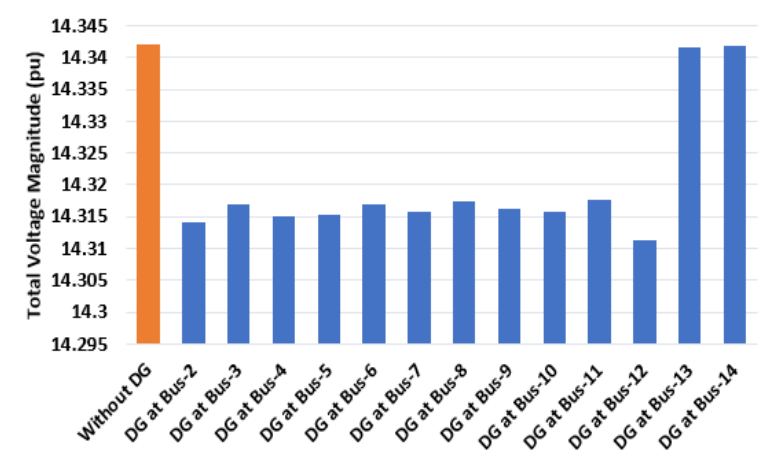

Figure 14. Change in total bus voltage magnitudes after DG insertion in each bus

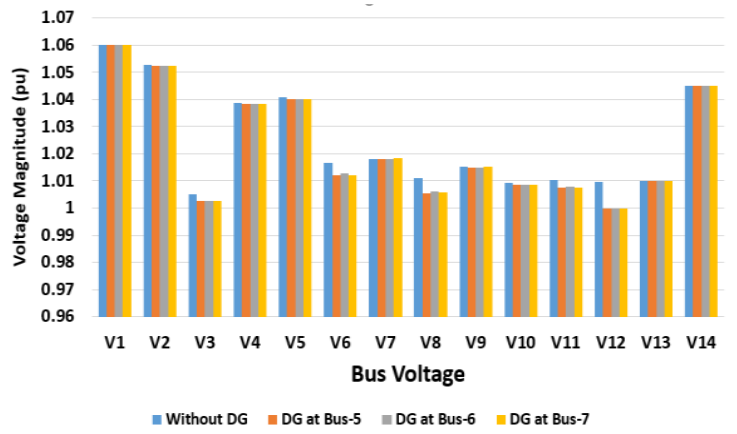

Figure 11. Change in each bus voltage magnitudes after DG insertion at Bus-5 to Bus-7

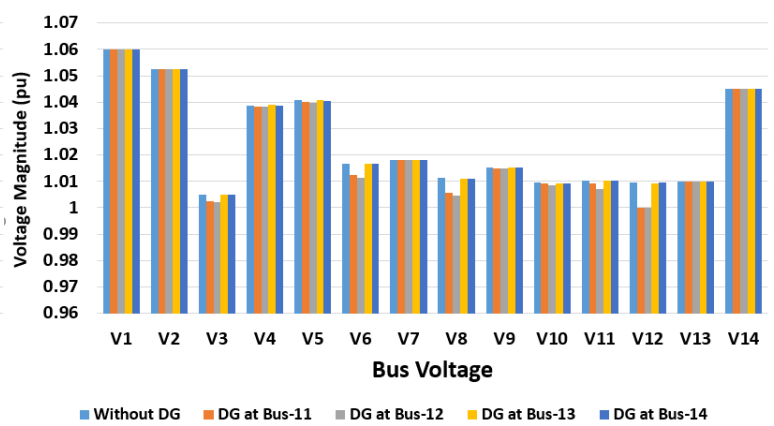

Figure 13. Change in each bus voltage magnitudes after DG insertion at Bus-11 to Bus-14

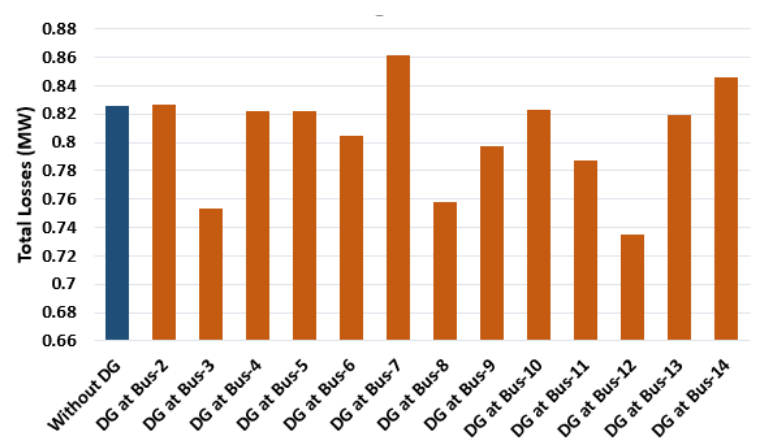

Figure 15. Change in total line to line loss after DG insertion in each bus

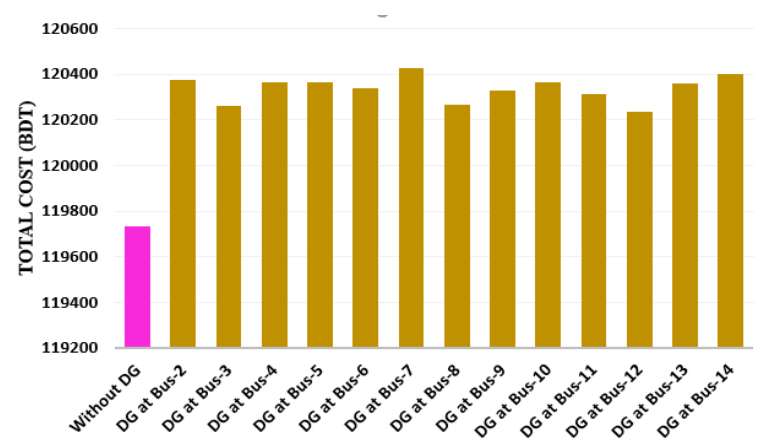

Figure 16. Change in total generation cost after DG insertion in each bus 
Table 5. Optimal decision for DG placement

\begin{tabular}{ccccc}
\hline \multirow{2}{*}{$\begin{array}{c}\text { DG } \\
\text { Placement }\end{array}$} & \multicolumn{3}{c}{ Total Change in $\%$} & \\
\cline { 2 - 4 } & Loss & Voltage & Cost & Decision \\
$(\mathrm{MW})$ & 0.825 & 14.342 & 1420.5 & \\
\hline Without DG & $($ USD) & \\
Bus-2 & $(+) 1.05$ & $(+) 0.19$ & $(+) 0.53$ & \\
Bus-3 & $(-) 10.7$ & $(+) 0.18$ & $(+) 0.44$ & \\
Bus-4 & $(-) 0.52$ & $(+) 0.19$ & $(+) 0.54$ & \\
Bus-5 & $(-) 0.52$ & $(-) 0.17$ & $(+) 0.53$ & \\
Bus-6 & $(-) 2.60$ & $(-) 0.13$ & $(+) 0.51$ & \\
Bus-7 & $(+) 4.30$ & $(+) 0.16$ & $(+) 0.58$ & \\
Bus-8 & $(-) 8.22$ & $(+) 0.15$ & $(+) 0.45$ & \\
Bus-9 & $(-) 3.50$ & $(+) 0.18$ & $(+) 0.50$ & \\
Bus-10 & $(-) 0.41$ & $(-) 0.18$ & $(+) 0.53$ & \\
Bus-11 & $(-) 4.66$ & $(+) 0.19$ & $(+) 0.49$ & \\
Bus-12 & $(-) 11.0$ & $(+) 0.18$ & $(+) 0.42$ & Selected \\
Bus-13 & $(-) 0.81$ & 0.00 & $(+) 0.53$ & \\
Bus-14 & $(+) 2.36$ & $(-) 0.17$ & $(+) 0.56$ & \\
\hline
\end{tabular}

\section{COMPARISON WITH STATIC LOADS}

In the literature study most of the researcher has solved the multi objective optimization for static loads which are usually considered as the maximum demand during a particular time of span for a network [24]. If the given system is analyzed for corresponding maximum loads of Figure 17 and Figure 18 for the same section of the network with yearly same time of span. Corresponding change in total bus voltage, line to line loss and generation cost for static loads of the network are depicted in Figure 19 to Figure 21. Optimal decision for DG placement is found bus number 8 for static loads from Table 6. It is clear that, optimized value varies due to the load variation in any time span.

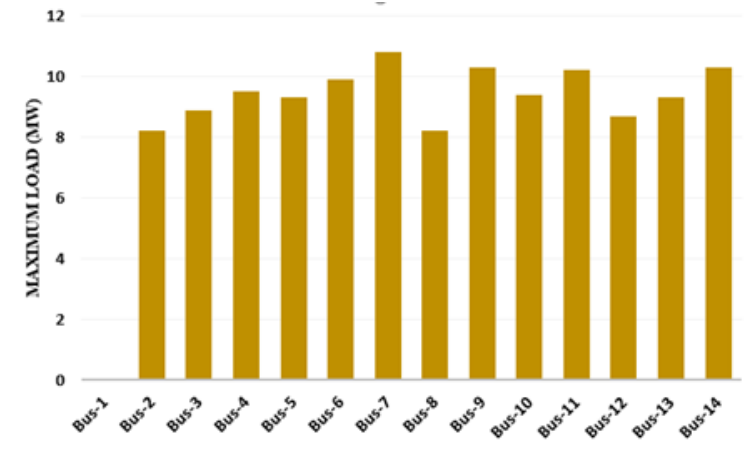

Figure 17. Maximum loads of the network in each bus (Real power)

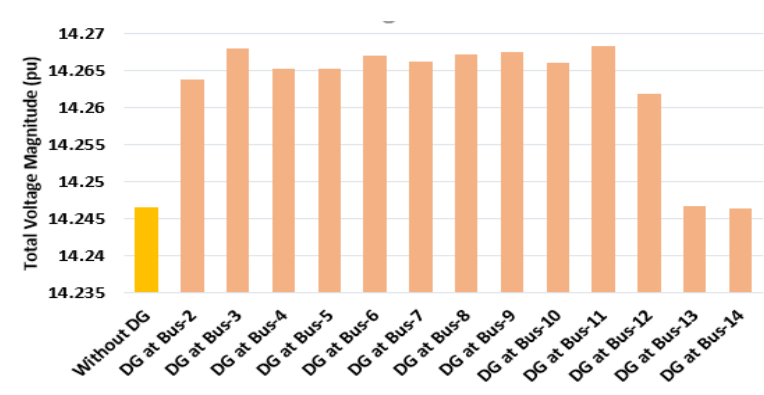

Figure 19. Change in total bus voltage magnitudes after DG insertion in each bus (Static Load)

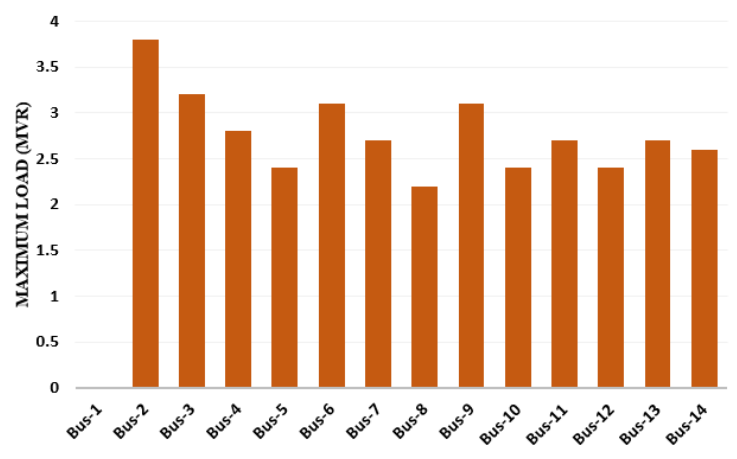

Figure 18. Maximum loads of the network in each bus (Reactive power)

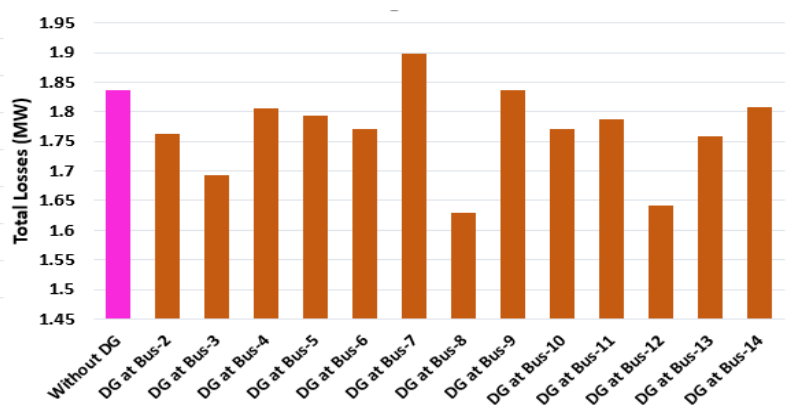

Figure 20. Change in total line to line loss after DG insertion in each bus (Static Load) 


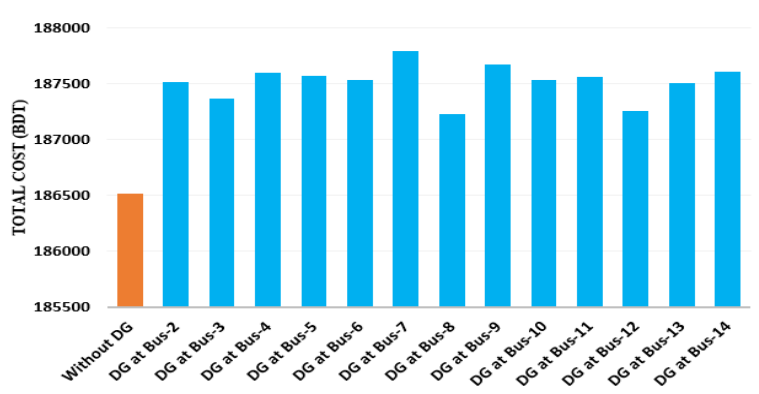

Figure 21. Change in total line to line loss after DG insertion in each bus (Static Load)

Table 6. Optimal decision for DG placement

\begin{tabular}{ccccc}
\hline \multirow{2}{*}{$\begin{array}{c}\text { DG } \\
\text { Placement }\end{array}$} & \multicolumn{3}{c}{ Total Change in } & \\
\cline { 2 - 4 } & $\begin{array}{c}\text { Loss } \\
(\mathrm{MW})\end{array}$ & $\begin{array}{c}\text { Voltage } \\
(\mathrm{pu})\end{array}$ & $\begin{array}{c}\text { Cost } \\
\text { (USD) }\end{array}$ & \\
\hline Without DG & 1.84 & 14.246 & 2212.9 & \\
Bus-2 & $(-) 3.99$ & $(+) 0.12$ & $(+) 0.53$ & \\
Bus-3 & $(-) 7.80$ & $(+) 0.15$ & $(+) 0.45$ & \\
Bus-4 & $(-) 1.64$ & $(+) 0.13$ & $(+) 0.58$ & \\
Bus-5 & $(-) 2.35$ & $(-) 0.13$ & $(+) 0.57$ & \\
Bus-6 & $(-) 3.53$ & $(+) 0.14$ & $(+) 0.54$ & \\
Bus-7 & $(+) 3.33$ & $(+) 0.14$ & $(+) 0.68$ & \\
Bus-8 & $(-) 11.3$ & $(+) 0.15$ & $(+) 0.38$ & Selected \\
Bus-9 & $(+) 0.08$ & $(+) 0.15$ & $(+) 0.62$ & \\
Bus-10 & $(-) 3.51$ & $(+) 0.14$ & $(+) 0.54$ & \\
Bus-11 & $(+) 2.70$ & $(+) 0.15$ & $(+) 0.56$ & \\
Bus-12 & $(-) 10.6$ & $(-) 0.11$ & $(+) 0.40$ & \\
Bus-13 & $(-) 4.21$ & $(+) 0.00$ & $(+) 0.53$ & \\
Bus-14 & $(-) 1.49$ & $(-) 0.10$ & $(+) 0.58$ & \\
\hline
\end{tabular}

In modern days, load variation is one of the common problem for electrical network systems specially for distribution sectors. These loading effect issue cannot be ignored during analysing optimization problem. For the given system considering loading effect system optimal decision ensures $2.78 \%$ less line to line loss, $0.03 \%$ more bus voltage improvement and $0.03 \%$ less generation cost in a year. Different types of load curves need to be analysed for effective solution of optimization problem for uncertain load conditions of the network.

\section{CONCLUSION}

The integration of DG units in power system networks has become more protruding to revamp overall system efficiency by augmenting system voltage magnitudes, assuaging power losses and dwindling total generation cost. In this work, an algorithm is proposed to locate DG in the optimal bus location with multiple number of objective function and constraints of N-bus network. The developed adaptive algorithm provides the most appeasement and admissible result among all the approach discussed in the literature study especially for different load characteristics. The convergence criterion of the algorithm is well acceptable for not only time invariant but also time variant loads. The probabilistic dynamic load and generation model ensconce the optimal place of DG without violating the thermal limit and other constraints of the network. Due to the load and generation uncertainty, the system has different bus location at static and dynamic loading conditions. From this work, it is clear that final decision for optimal placement of DG need to take on considering dynamic loading conditions due to the large variations in load characteristics of power system networks.

\section{REFERENCES}

[1] Masaud, T.M., Nannapaneni, G. and Challoo, R. "Optimal placement and sizing of distributed generation-based wind energy considering optimal self VAR control," IET Renewable Power Generation, Vol. 11 Issue 3, pp. 281-288, 2017.

[2] Hossain, S. M. and Hasan, M. M. "Energy Management through Bio-gas based Electricity Generation System during Load Shedding in Rural Areas," TELKOMNIKA Telecommunication Computing Electronics and Control, Volume16, Issue-2, pp: 525-532, April 2018. 
[3] Hossain, S. M. and Chowdhury, A. H. "Optimal Placement of Distributed Generation to Enhance Bus Voltage Qualitative Index," International Journal of Engineering and Technology (IJET), Dec 2018-Jan 2019, Volume 10, Issue 6, pp. 1778-1786, 2019.

[4] Keane, A., Ochoa, L.F. "State-of-the-Art Techniques and Challenges Ahead for Distributed Generation Planning and Optimization," IEEE Transaction on Power Systems, vol. 28, no. 2, pp. 1493-1502, 2013,

[5] Naik, G., Khatod, D.K. and Sharma, M. P. "Optimal Allocation of Distributed Generation in Distribution System for Loss Reduction," IPCSIT vol. 28, IACSIT Press, Singapore, pp 42-46, 2012.

[6] Dulua, L. I. "Optimization of a Power System with Distributed Generation Source," 9th International Symposium on Advanced Topics in Electrical Engineering, Bucharest, Romania, pp. 903-906, May 7 9, 2015.

[7] Keane, A., Nando, L., Ochoa, F., Vittal, E., Dent, C. J. and G. Harrison, H. "Enhanced Utilization of Voltage Control Resources with Distributed Generation," IEEE Transactions on Power Systems, Volume: 26, Issue 1, pp. $252-260,2011$.

[8] Kayal, P. and Chanda, C.K. "A simple and fast approach for allocation and size evaluation of distributed generation," International Journal of Energy and Environmental Engineering (Springer), Vol. 4, Issue. 7, pp. 1-9, 2013.

[9] Parizad, A., Khazali, A., Kalantar, M. "Optimal Placement of Distributed Generation with Sensitivity Factors Considering Voltage Stability and Losses Indices," Proceedings of 18th Iranian Conference on Electrical Engineering (ICEE), Isfahan, Iran, May 11 13, 2010.

[10] Prakasha, D.B., Lakshminarayanab, C. "Multiple DG Placements in Distribution System for Power Loss Reduction Using PSO Algorithm,” Procedia Technology (Elsevier), Volume 25, pp. 785 - 792, 2016.

[11] Kumar, M., Nallagownden, P. and Elamvazuthi, I. "Optimal Placement and Sizing of Renewable Distributed Generations and Capacitor Banks into Radial Distribution Systems,” Energies-2017, Volume 10, pp. 1-24, 2017.

[12] Sahib, T.J., Ghani, M.R.A., Jano, Z. "Optimum Allocation of Distributed Generation using PSO: IEEE Test Case Studies Evaluation," International Journal of Applied Engineering Research, Volume 12, Number 11, pp. 1-19, 2017.

[13] Khosravi. M. "Optimal Placement of Distributed Generation Sources in Order to Reduce Loss and Improve Voltage Profiles in Power Distribution Networks Using Genetic Algorithms," European Online Journal of Natural and Social Sciences, Vol. 3, No. 3. pp. 332-342, 2014.

[14] Kollu, R., Rayapudi. S.R. and Venkata "A novel method for optimal placement of distributed generation in distribution systems using HSDO," International Transactions on Electrical Energy Systems, Vol. 24, pp. 547-561, 2014.

[15] Singh, N., Ghosh, Murari, S.K. "Optimal Sizing and Placement of DG in a Radial Distribution Network using Sensitivity based Methods," International Electrical Engineering Journal (IEEJ), Vol. 6, No.1, pp. 1727-1734, 2015.

[16] Aman, M.M., Jasmon, G.B., Mokhlis, H., Bakar, A.H.A. "Optimal placement and sizing of a DG based on a new power stability index and line losses," Electrical Power and Energy Systems (Elsevier), Vol. 43, pp. 1296-1304, 2012.

[17] Nasab, M.A. and Mohammad, M. "PSO Based Multi-Objective Approach for Optimal Sizing and Placement of Distributed Generation," Research Journal of Applied Sciences, Engineering and Technology, 2(8): pp 832-837, 2011.

[18] Jamian, J.J., Mustafa, M. W., Mokhlis, H. and Baharudin, M.A. "Implementation of Evolutionary Particle Swarm Optimization in Distributed Generation Sizing," International Journal of Electrical and Computer Engineering (IJECE), Vol. 2, No. 1, February 2012, pp. 137-146, 2012.

[19] Junjie, M.A., Yulong, W., Yang, L. "Size and Location of Distributed Generation in Distribution System Based on Immune Algorithm," Procedia Systems Engineering (Elsevier), Volume 4, pp. 124 - 132, 2012.

[20] Reddy, S.C., Prasad, P.V.V., and Laxmi, A.J. "Power Quality Improvement of Distribution System by Optimal Placement and Power Generation of DGs using GA and NN," European Journal of Scientific Research, Vol.69, No.3, pp. 326-336, 2012.

[21] Abedini, M. and Saremi, H. "A Hybrid of GA and PSO for Optimal DG Location and Sizing in Distribution Systems with Load Uncertainty," Journal of Basic Applied Science Research, vol-2, issue-5, pp. 5103-5118, 2012.

[22] Donadel, C.B., Fardin, J.F., and Frizera, L. "Optimal Placement of Distributed Generation Units in a Distribution System with Uncertain Topologies using Monte Carlo Simulation," International Journal of Emerging Electric Power Systems, Volume 16 Issue 5, pp. 1-11, 2015.

[23] "Yearly zone wise load characteristics in Bangladesh," http://www.bpdb.gov.bd' accessed on 13 June 2018.

[24] El-Zonkoly, A.M. "Optimal placement of multi-distributed generation units including different load models using particle swarm optimisation,” IET Generation Transmission Distribution, Vol. 5, Issue 7, pp. 760-771, 2011. 